\title{
Article
}

\section{The Effect of a Flexible Blade for Load Alleviation in Wind Turbines}

\author{
Azael Duran Castillo ${ }^{1}$, Juan C. Jauregui-Correa $\left.{ }^{1}{ }^{(}\right)$, Francisco Herbert ${ }^{2}$, Krystel K. Castillo-Villar ${ }^{2}{ }^{\mathbb{D}}$, \\ Jesus Alejandro Franco ${ }^{3, *} * \mathbb{D}$, Quetzalcoatl Hernandez-Escobedo ${ }^{3, *} \mathbb{}$, Alberto-Jesus Perea-Moreno ${ }^{4, *}$ \\ and Alfredo Alcayde ${ }^{5, *}$ (1)
}

1 Faculty of Engineering, Universidad Autonoma de Queretaro, Cerro de las Campanas S/N, Queretaro 76010, Mexico; aduran116@alumnos.uaq.mx (A.D.C.); jc.jauregui@uaq.mx (J.C.J.-C.)

2 Mechanical Engineering Department, Texas Sustainable Energy Research Institute, University of Texas at San Antonio, One UTSA Circle, San Antonio, TX 78249, USA; francisco.herbert@utsa.edu (F.H.); krystel.castillo@utsa.edu (K.K.C.-V.)

3 Escuela Nacional de Estudios Superiores Unidad Juriquilla, UNAM, Queretaro 76230, Mexico

4 Departamento de Física Aplicada, Radiología y Medicina Física, Universidad de Córdoba, Campus de Rabanales, 14071 Córdoba, Spain

5 Department of Engineering, University of Almería, La Cañada de San Urbano, 04120 Almería, Spain

* Correspondence: alejandro.francop@unam.mx (J.A.F.); qhernandez@unam.mx (Q.H.-E.); aperea@uco.es (A.-J.P.-M.); aalcayde@ual.es (A.A.)

check for updates

Citation: Castillo, A.D.; Jauregui-Correa, J.C.; Herbert, F.; K. Castillo-Villar, K.; Franco, J.A.;

Hernandez-Escobedo, Q.;

Perea-Moreno, A.-J.; Alcayde, A. The Effect of a Flexible Blade for Load Alleviation in Wind Turbines. Energies 2021, 14, 4988. https:// doi.org/10.3390/en14164988

Academic Editor: Ahmed Abu-Siada

Received: 8 July 2021

Accepted: 10 August 2021

Published: 13 August 2021

Publisher's Note: MDPI stays neutral with regard to jurisdictional claims in published maps and institutional affiliations.

Copyright: (c) 2021 by the authors. Licensee MDPI, Basel, Switzerland. This article is an open access article distributed under the terms and conditions of the Creative Commons Attribution (CC BY) license (https:/ / creativecommons.org/licenses/by/ $4.0 /)$.

\begin{abstract}
This article presents the analysis of the performance of a flexible wind turbine blade. The simulation analysis is based on a $3 \mathrm{~m}$ span blade prototype. The blade has a flexible surface and a cam mechanism that modifies the aerodynamic profile and adapts the surface to different configurations. The blade surface was built with a flexible fiberglass composite, and the internal mechanism consists of a flexible structure actuated with an eccentric cam. The cam mechanism deforms five sections of the blade, and the airfoil geometry for each section was measured from zero cam displacement to full cam displacement. The measured data were interpolated to obtain the aerodynamic profiles of the five sections to model the flexible blade in the simulation process. The simulation analysis consisted of determining the different aerodynamic coefficients for different deformed surfaces and a range of wind speeds. The aerodynamic coefficients were calculated with the BEM method (QBlade ${ }^{\circledR}$ ); as a result, the data performance of the flexible blade was compared for the different deformation configurations. Finally, a decrease of up to approximately $6 \%$ in the mean bending moment suggests that the flexible turbine rotor presented in this article can be used to reduce extreme and fatigue loads on wind turbines.
\end{abstract}

Keywords: wind energy; deformable profile; efficiency; wind turbine; renewable energy

\section{Introduction}

Growing concerns about global warming, environmental pollution, and energy security have increased interest in developing renewable and environmentally friendly energy sources. Electricity generation is the most significant driver of emissions; electricity/heat generation produces two-thirds of all greenhouse gases. A global energy transition is urgent to mitigate the changes occurring on earth, such as current global warming. The energy transition requires technological innovations to create increasingly efficient renewable energy systems [1].

Nowadays, wind and solar power dominate growth in renewable energy generation, according to the roadmap global energy model of the International Renewable Energy Agency (IRENA) that analyzes the technical and economic parameters of an energy transition to 2050. Wind energy can provide suitable solutions for global climate change and the energy crisis; this energy resource will occupy $24 \%$ of renewables in total final energy consumption terms by 2050 [2]. 
The constant growth of wind turbine capacities has required the research and development of novel control strategies to reduce stress loads on the blades as well as increase performance and efficiency by reducing the cost per kWh of energy produced. This problem control has been approached from different perspectives by researchers today. Several studies have studied new classical methods with advanced pitch control, such as Zhang and Plestan [3] who proposed a new control strategy that combines collective and individual blade pitch control for power regulation. The control system showed a high-level of performance. Colombo et al. [4] proved a robust sliding mode approach control using the pitch as a control input; the proposed solution was validated through simulation of a $5 \mathrm{MW}$ wind turbine; similarly, a novel control was presented by Wiens et al. [5]. This method was used to mitigate the gust effects using a collective twist and pitch control; as a result, the simulations revealed that this control could lead to the reduction of loads in the turbine. Recent studies have proposed new designs of rotors with double-pitched blades; these new techniques have a similar principle as active smart rotors since they are based on modifying the blade pitch angle in independent sections along the blade; the simulation results of the study showed flutter suppression [6]. However, with the growth in the diameters of the current wind turbines, faster and more efficient controls have become more critical. Currently, a large sector of research has suggested the use of smart blade techniques in wind turbines; these smart rotors are capable of modifying or adapting the blade profile in response to various operating conditions with the integration of several sections with active elements. The main objective of these elements is a fast response to the changes in the operating variables that would, thereby, reduce loads in real-time.

The technology behind smart rotors can be divided into two main strategies. The first is the use of rigid structures that change aerodynamic geometry through trailing and leading edge fins or ailerons, such as Bernhammer et al. [7] who analyzed the reductions in fatigue and extreme loads of wind turbine components using an individual flap. As a result, they demonstrated a fatigue load reduction of the blade root bending of $24 \%$. Oltmann et al. [8] investigated the feasibility of using trailing edge flaps as an active control mechanism for load reduction; the results revealed a configuration that eliminated the cyclic variation of the blade root bending moment. Sun et al. [9] designed and simulated an external blade-flap configuration for wind turbine blades. A reduction in the fluctuation of the blade root bending was obtained as a result. A study carried out by Chen and Qin [10] showed the performance of trailing-edge flow control devices such as microtabs, microjets, and a divergent trailing edge; the simulation results showed the advantages and disadvantages of the use of these devices in wind turbines. Boulamatsis et al. [11] presented an active control concept based on the blade tip sweep variation as a constant fatigue load alleviator.

In recent studies, several solutions have been proposed to implement deformable structures with flexible and continuous surfaces in the blades of wind turbines. These structures have shown significant advantages over smart rotors that use rigid elements due to the rigid structures that produce discontinuities in the aerodynamic surfaces of the blades, as well as the use of elements with mechanical wear such as various joints or external bearings that generate frequent maintenance, reduce operating costs, and aerodynamic efficiency. Lachenal et al. [12] presented a review of the active morphing concepts and the details of candidate materials for morphing structures in wind turbines; they concluded that the future of the next-generation wind turbines would be the integration of these compliant structures into blades that provide more efficiency and increase the turbine life. Jost et al. [13] studied the aerodynamics effects and influence of a rotor with trailing edge flaps on a wind turbine; they confirmed the necessity to consider the 3D effects in the design of trailing edge flaps. Rasmussen and Johansen [14] developed a rotor with flexible blades; this rotor showed advantages against a standard rotor in experimental tests. In this way, Momeni et al. [15] analyzed the performance of a novel plant leaf-mimetic wind blade; the results showed that this design may solve flutter issues in wind turbines. Franco et al. $[16,17]$ developed a method to optimize the efficiency of wind turbine blades 
by modifying the aerodynamic profile and demonstrated the applicability of the shape morphing concept with the integration of a mechanism to deform the profile of a wind turbine blade. Its design considers two actuators; one to deform the leading edge and the second to curve the trailing edge. A study carried out by Khakpour and Hall [18] proposed a methodology for designing a blade with flexible modular segments; this blade uses five actuators and can achieve a full range of twist angle distribution.

The advances in new materials have led to the implementation of the concept of shape morphing in more studies In this way, Cognet et al. [19] proposed a method that finds the optimal soft materials of flexible blades to maximize the turbine efficiency by up to $+35 \%$. Similarly, MacPhee and Beyene [20] examined a morphing bladed turbine through experimental and numerical analysis; as a result, they found the flexible design outperforms the rigid design and increases the power coefficient by up to $+32.6 \%$. Zhuang et al. [21] studied the effect of a morphed trailing edge flap on the aerodynamic load control in a large wind turbine blade; the simulations revealed excellent load control capability. According to this, it is possible to observe the advantages that have been found due to the use of the shape morphing concept in wind turbines from the point of view of increasing the total efficiency of the turbine as well as controlling the load, reducing costs, and increasing the useful life of the overall renewable energy system.

In this article, the analysis is based on the paper presented by Jauregui et al. [22] who developed a novel blade design with deformable airfoil sections; the blade deformation changes from a baseline airfoil to another aerodynamic profile depending on the actuation of the cam mechanism; in this way, a singular elastic element that represents the line of the profile chord follows a third-order polynomial path. Figure 1 shows the shape morphing mechanism, which consists of a flexible strip (leaf spring) parallel to the airfoil chord, and a leaf spring attached to the blade external profile through rigid posts. These posts transmit the spring deflections to the flexible surface, and a cam mechanism moves the leaf spring, controlling the vertical displacements of the posts.

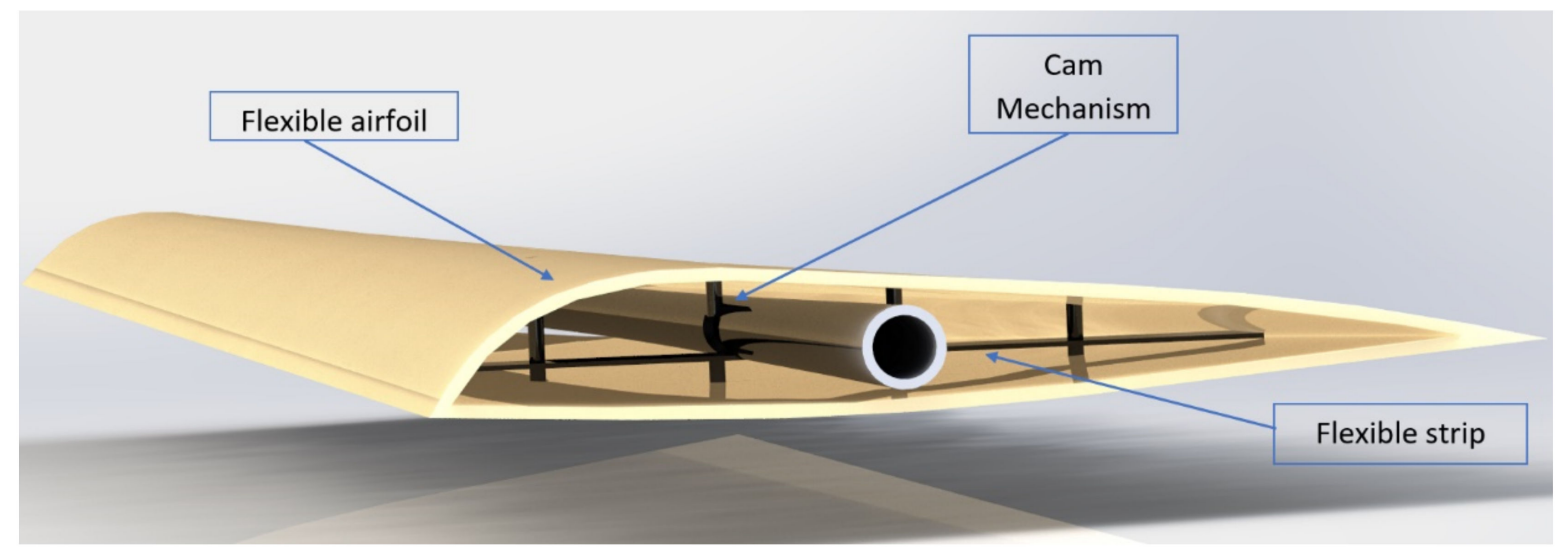

Figure 1. Shape morphing mechanism.

The inner structure of the flexible blade is revealed in Figure 2; the leading and trailing edge reinforcements provide the blade rigidity and the flexibility is achieved by the combination of the resins. In the figure, it can be observed that the cam and flexible strips positions are inside the flexible blade; the materials used in the manufacturing process of the blade prototype allowed achievement of local deformations without deforming the material in the chord direction. The Horizontal Axis Wind Turbine (HAWT) base rotor was designed with an optimal Tip Speed Ratio (TSR) equaling 6, and a configuration of the base profiles that corresponds to zero cam displacement. The rotation of the cam mechanism is carried out with the aim of obtaining maximum performance, maintaining an optimal energy capture, and reducing loads when the turbine experiences changes in operating conditions. This article seeks to demonstrate the benefits of using a flexible blade based on a simple cam mechanism to reduce loads on wind turbine rotors. Future work is necessary 
to formulate the control and instrumentation models to represent an overall load control strategy for wind turbines.

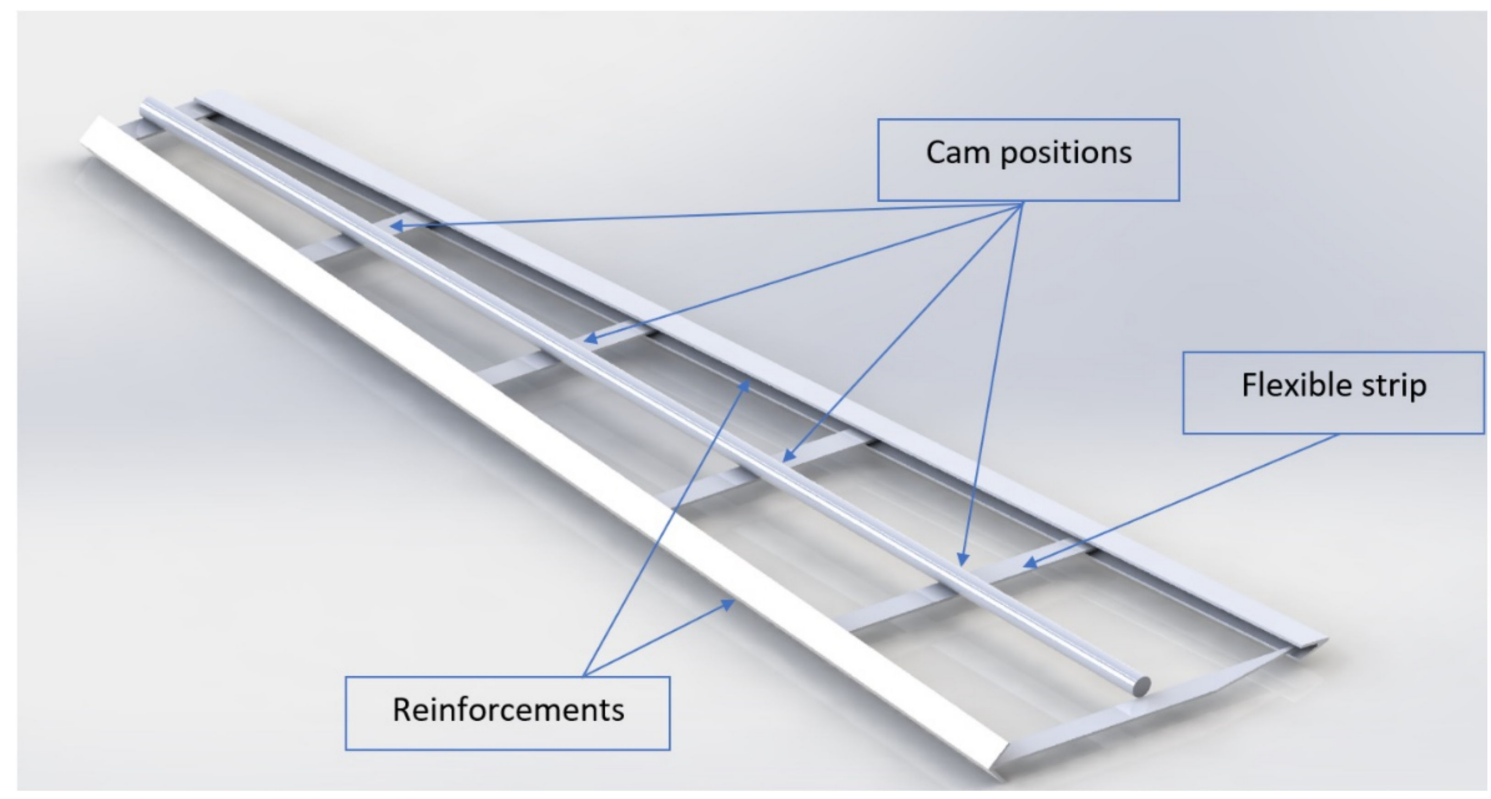

Figure 2. Inner structure of the flexible blade.

The article is divided into four main sections. Section 1 describes the state of the art technologies used in wind turbine smart rotors; in Section 2, the methodology for evaluating the power increment of the shape morphing blade design is established. For this purpose, the airfoil geometry for each cam section of the blade was measured setting the cam mechanism at different angles to implement the BEM simulations with the software QBlade ${ }^{\circledR}$; the simulation results and discussions are revealed in Section 3; finally, in Section 4 the conclusions of the paper and future work are presented.

\section{Materials and Methods}

\subsection{Flexible Blade Prototype}

The prototype analyzed in this article is a $3.1 \mathrm{~m}$ long blade made with two types of resins: a flexible resin with $69 \%$ polyester and $31 \%$ styrene, and a rigid resin with $51 \%$ styrene and $49 \%$ polyester with a proportion of $60 \%$ rigidity and $40 \%$ flexibility with a fiberglass-reinforced core; Young's modulus is $270 \mathrm{GPa}$, the yield point is $93,600 \mathrm{MPa}$, and the deformation is $0.0001656 \mathrm{~mm} / \mathrm{mm}$. Inside the blade, the eccentric cam mechanism, which rotates the axis along the blade, deforms the spring located in the chord of the aerodynamic profile in a singular cam section. The chord changes from a horizontal baseline to a third-order polynomial shape.

The airfoil geometry was measured at the location of the five eccentric cams on the lowpressure (upper) and high-pressure (lower) surfaces of the airfoil. The measurement points are localized by seven points across the width of both surfaces, and the measurements were performed at the different turning positions $\left(0^{\circ}, 30^{\circ}, 45^{\circ}, 60^{\circ}\right.$, and $90^{\circ}$ degrees $)$ of the cam mechanism of the flexible blade (Figure 3$)$. The displacements were recorded with a high precision dial sensor to obtain the data of the deformed airfoils along the blade for each configuration, which were used in the simulation process. 


\subsection{BEM Simulations}

One of the most critical parameters to evaluate the wind turbine performance is the power coefficient $C_{p}$; this is defined as the ratio between the power captured by the turbine $P$ and the wind power available in a swept area $A$ (see Equation (1))

$$
C_{P}=\frac{P}{\frac{1}{2} \rho A V^{3}}
$$

where $V$ is the wind velocity, and $\rho$ is the air density.

The power coefficient can be obtained by several mathematical models; in this article, the blade element momentum (BEM) method was selected due to its low computational cost; according to this, the BEM method allows us to analyze the performance of the shape morphing rotor for the different angles of the cam mechanism and a range of wind velocities.

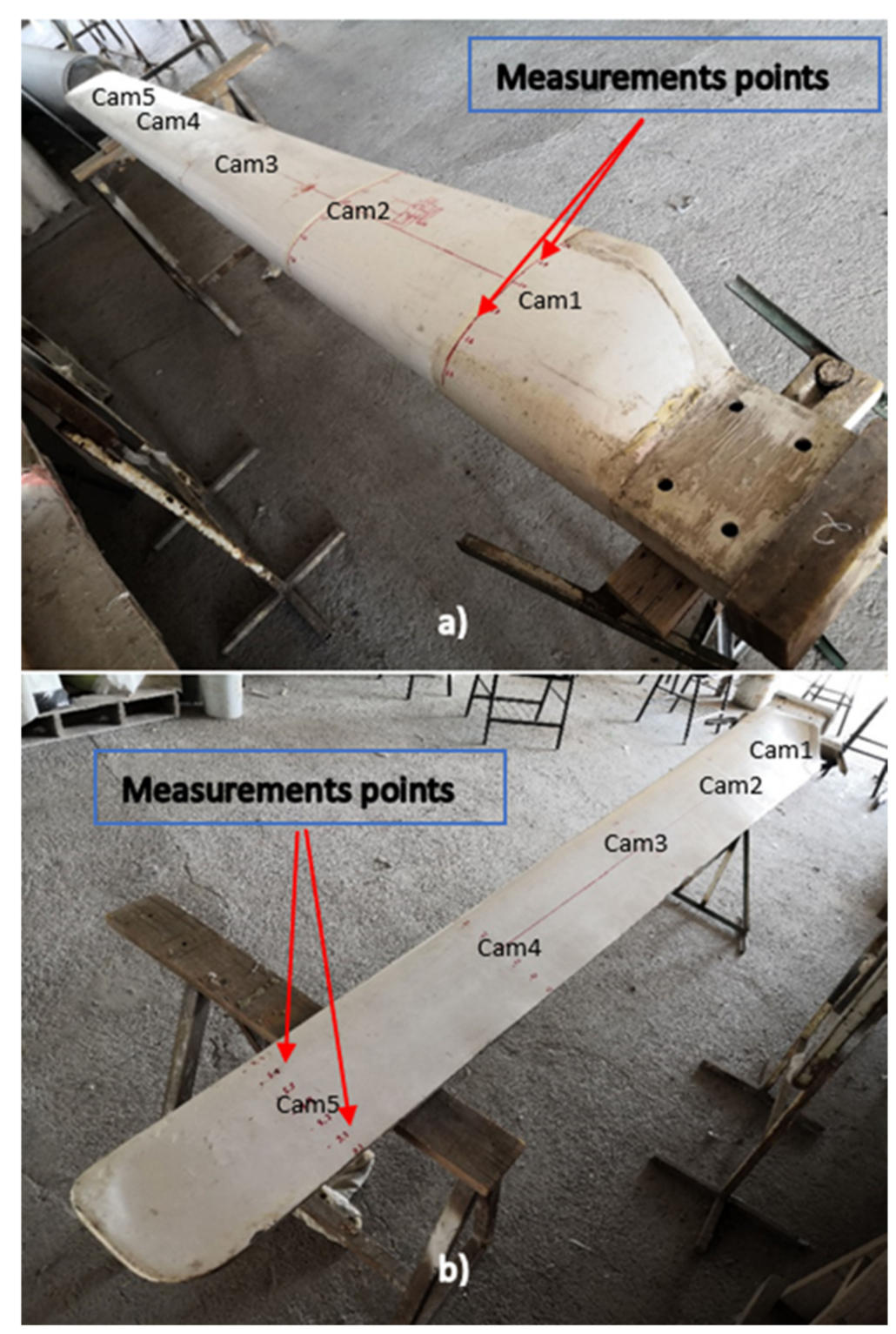

Figure 3. Location of measurement points (a) low-pressure surface (b) high-pressure surface. 
Figure 3a shows the measurement points located on the low-pressure (upper) surface of the blade, and the location of the corresponding points on the high-pressure surface is presented in Figure $3 b$.

The BEM method estimates the $C_{p}$ for a discretized blade through an iterative calculation of the induction factors; the axial $a$, and the tangential $a^{\prime}$, then the $C_{p}$ is given by Equation (2) [16]

$$
C_{P}=\frac{8}{\lambda^{2}} \int_{\lambda_{h}}^{\lambda} \lambda_{r}^{3} a^{\prime}(1-a)\left(1-\frac{C_{D}}{C_{L}} \arctan (\delta)\right) d \lambda_{r}
$$

where $\lambda$ is the tip speed ratio (TSR), $\lambda_{h}$ is the TSR in the hub position, $\lambda_{r}$ is the TSR for each radial position, and $\delta$ is the relative flow angle. The lift $C_{L}$ and $C_{D}$ drag coefficients are obtained from the following calculated with the XFoil software integrated into QBlade $^{\circledR}[23]$.

The QBlade ${ }^{\circledR}$ simulation procedure is summarized in the scheme of Figure 4. These stages were defined for each single blade deformation by the cam mechanism angle. The foil coordinates data were obtained through the measurements in the points in the surface of the blade (see Figure 3), and these values were introduced in the software in order to model the different aerodynamic profiles for each configuration of the cam mechanism; Figure 5 shows the different airfoils for the cam angle of $0^{\circ}$. This article presents a particular configuration and design of the cam mechanism along the flexible blade that belong to the airfoils shown in Table 1. These airfoil families have a modified NACA base by the cam mechanism displacement, and their references names were established by the authors (Mod 4638, Mod 4529, Mod 4530, etc.)

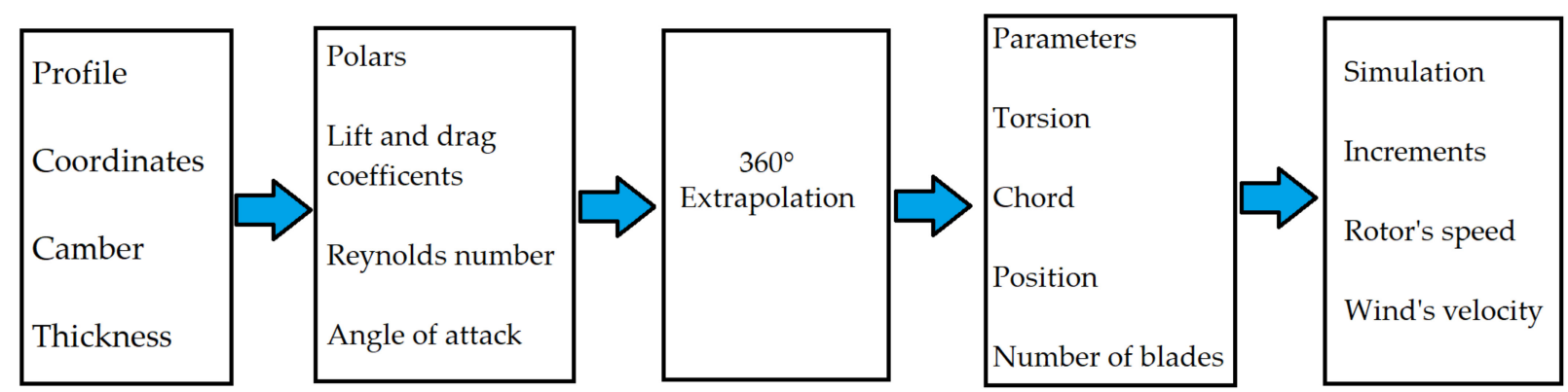

Figure 4. Wind turbine analysis using QBlade $^{\circledR}$.

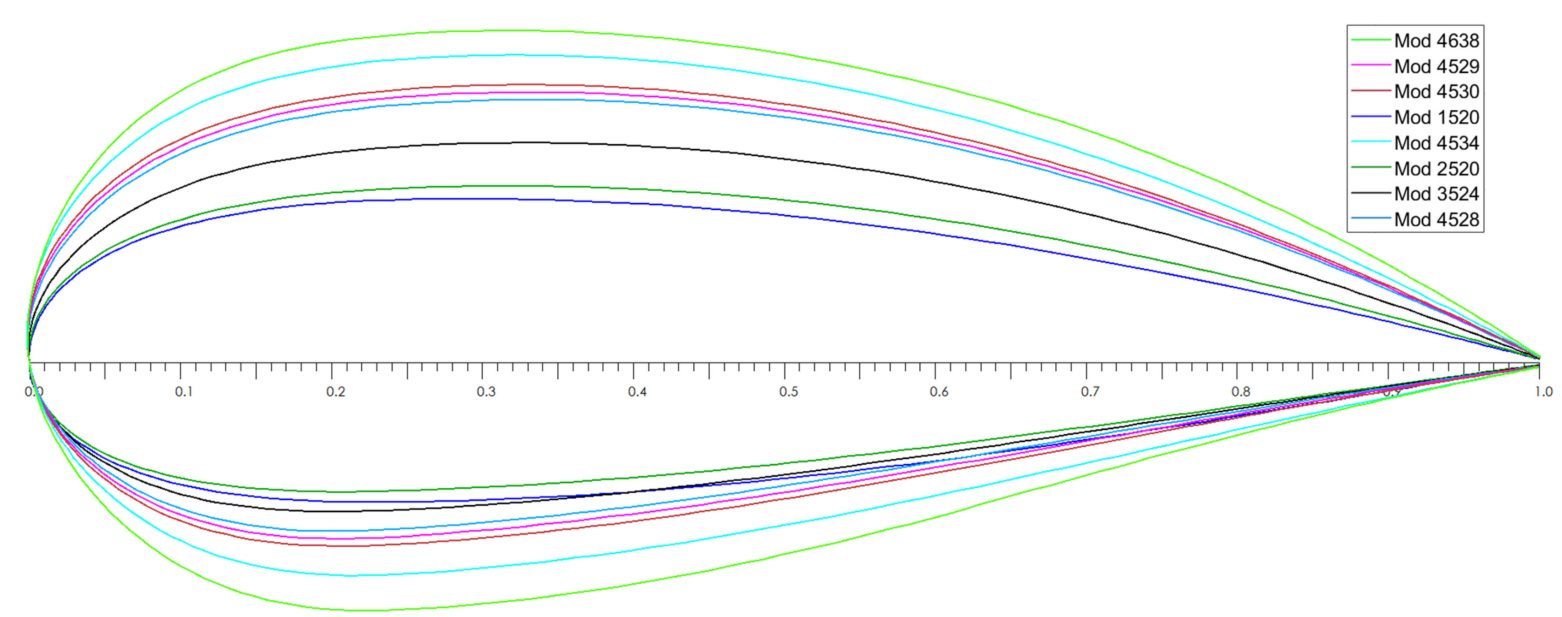

Figure 5. Blade airfoils at $0^{\circ}$ cam mechanism. 
Table 1. Blade design parameters without deformation $\left(0^{\circ}\right)$.

\begin{tabular}{ccccc}
\hline & Position $(\mathbf{m})$ & Airfoil (NACA Modified) & Chord (m) & ${\text { Angle }\left({ }^{\circ}\right)}^{\circ}$ \\
\hline & 0.000 & Circular & 0.220 & 0 \\
Section 1 & 0.195 & Circular & 0.220 & 0 \\
Section 2 & 0.400 & Mod 4638 & 0.332 & 13.42 \\
Cam 1 & 0.440 & Mod 4638 & 0.335 & 14.92 \\
Cam 2 & 0.568 & Mod 4634 & 0.328 & 13.44 \\
Section 3 & 1.070 & Mod 4530 & 0.307 & 5.71 \\
Section 4 & 1.230 & Mod 4530 & 0.301 & 5.06 \\
Cam 3 & 1.500 & Mod 4529 & 0.289 & 4.37 \\
Cam 4 & 1.708 & Mod 4528 & 0.280 & 2.37 \\
Cam 5 & 2.346 & Mod 3524 & 0.252 & 0.72 \\
Section 5 & 2.872 & Mod 2520 & 0.231 & 0.31 \\
Section 6 & 3.000 & Mod 1520 & 0.226 & 0.00 \\
& 3.100 & Mod 1520 & 0.223 & 0 \\
\hline
\end{tabular}

The blade was 3D modeled and introduced in QBlade ${ }^{\circledR}$ to process the BEM method; the BEM algorithm of QBlade ${ }^{\circledR}$ has been validated against experimental data and compared with different certified BEM tools [24]. The results presented in these studies showed a good accuracy/error relation with respect to the experimental data and the simulation results of the BEM tools compared.

Table 1 presents the blade data for the baseline blade (Cam $0^{\circ}$ ), and Figure 6 reveals the wind turbine blade model $\left(\mathrm{Cam} 0^{\circ}\right)$.

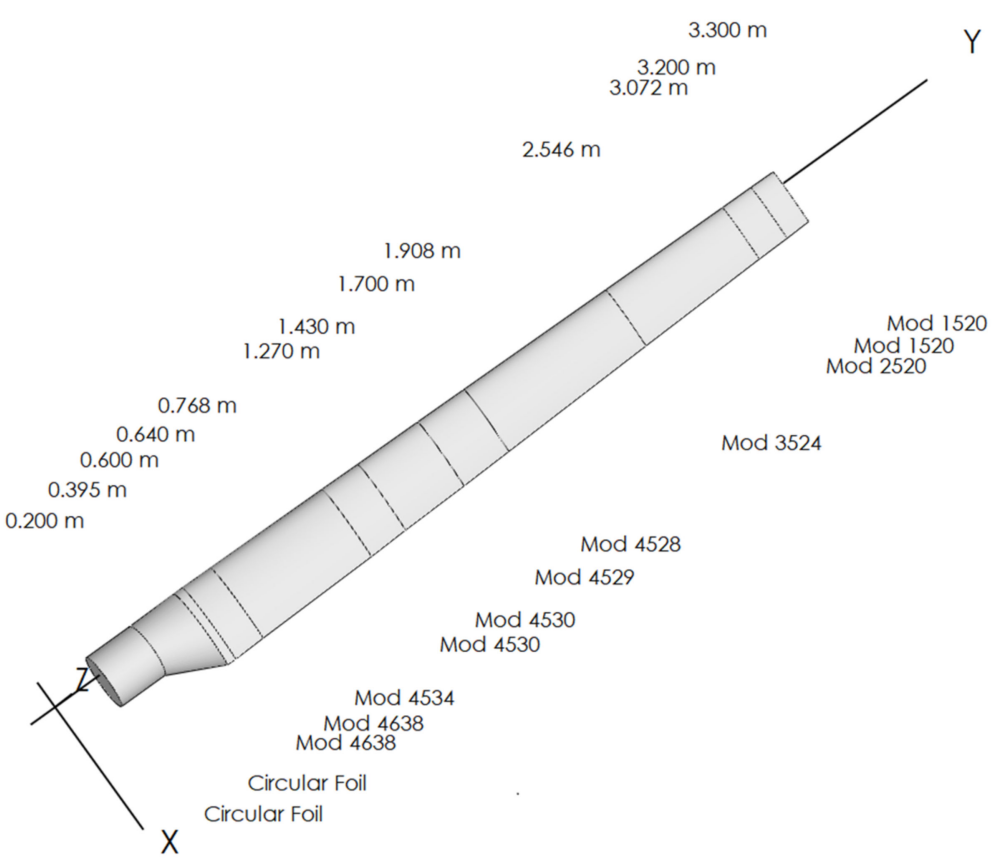

Figure 6. Blade model.

After this, the aerodynamics parameters of the different airfoils were calculated; an essential parameter for an airfoil design is the aerodynamic efficiency given by the ratio between $C_{L} / C_{D}$ (Figure 7); this parameter changes depending on the angle of attack of the blade section and was $360^{\circ}$ extrapolated by software for every single airfoil at the different cam configuration of the flexible blade.

Figure 8 presents the rotor model including parameters as the number of blades and hub radius equaling $0.2 \mathrm{~m}$. In the last stage of the BEM, simulations were established for the different operating parameters such as wind velocities, rotational speed, variable increments, among others; then, QBlade ${ }^{\circledR}$ calculated the output variables for the various configuration cam angles of the flexible blade wind turbine. Figure 9 shows the power 
output of the flexible rotor vs TSR for the different cam angles at $6 \mathrm{~m} / \mathrm{s}$; this process was repeated for a range of wind speeds to obtain a set of data to compare different blade deformations presented in the next section.

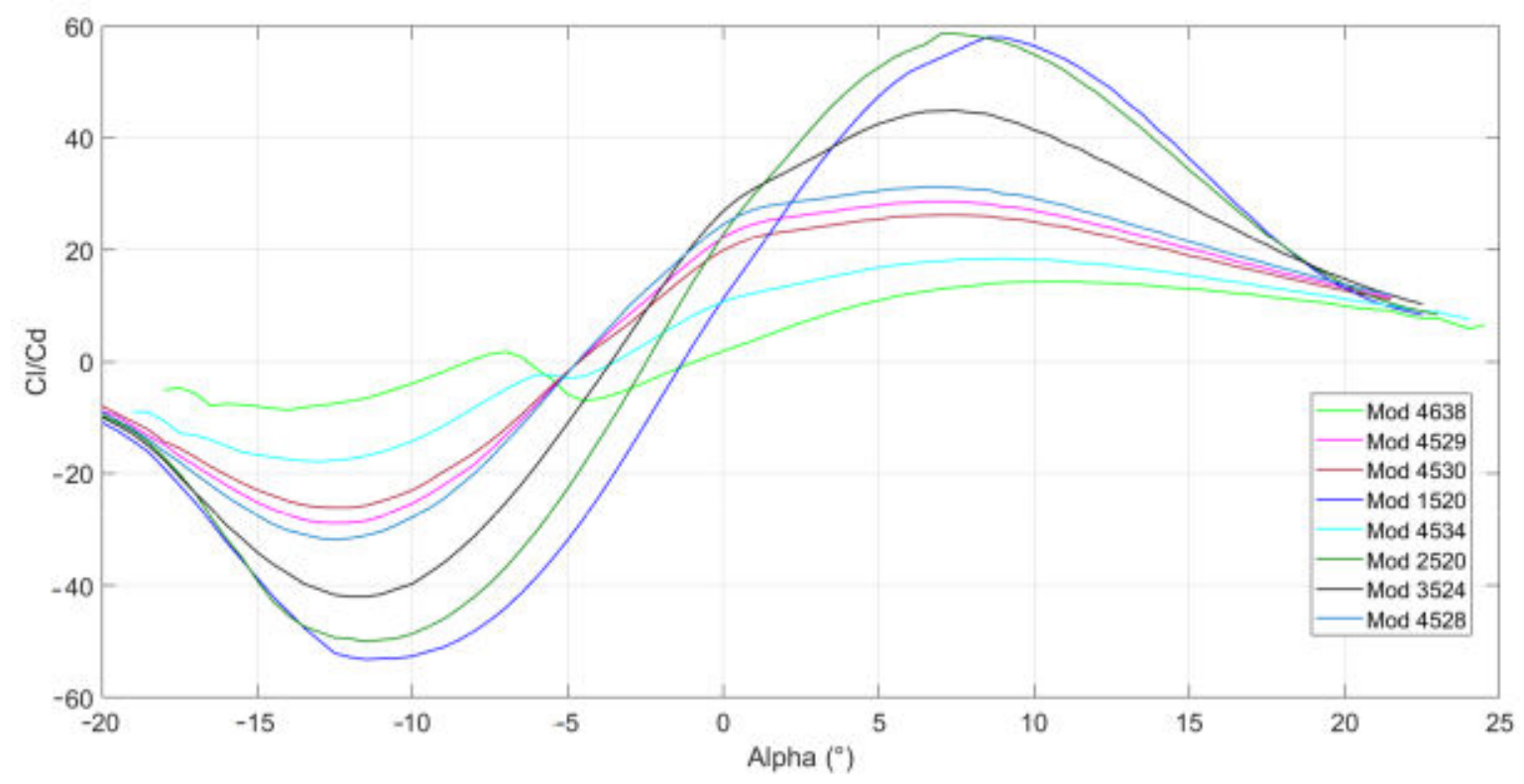

Figure 7. $C_{L} / C_{D}$ vs angle of attack.

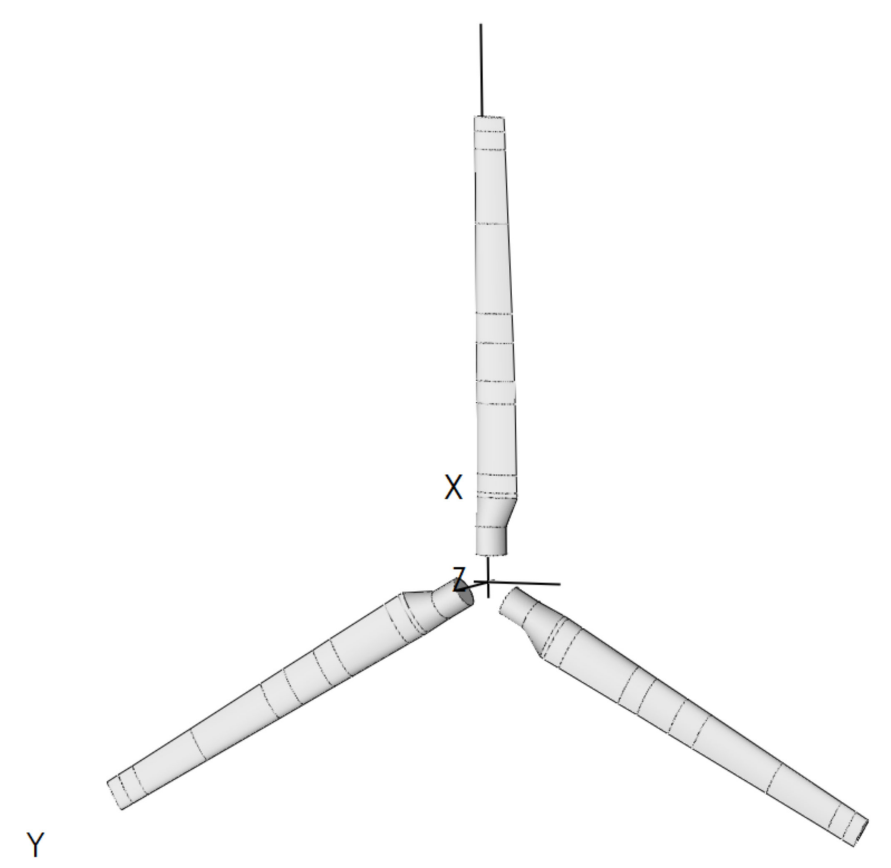

Figure 8. Three-blade rotor model.

In the simulation process, different variables were analyzed, among them one of great importance such as the thrust coefficient $C_{t}$; this was evaluated for the different deformations of the blade and at different wind speeds. From Figure 10 it is possible to infer that at different TSR values the same geometry deformed by the angle of the cam can generate maximum or minimum values in the thrust coefficient; these capabilities of the flexible rotor to control the bending moments of the turbine could result in a relevant strategy for load control. 


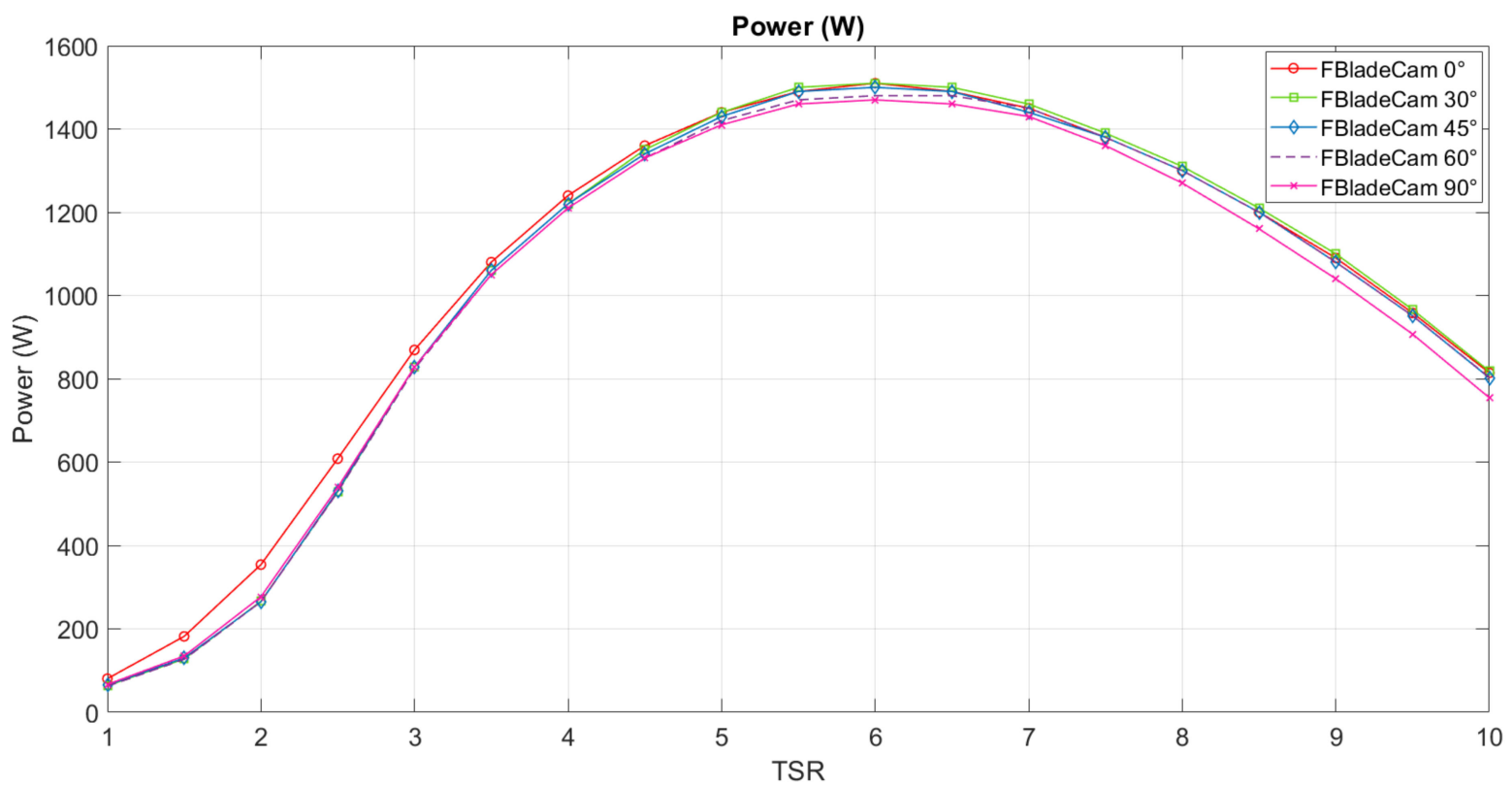

Figure 9. Power (W) vs TSR at $6 \mathrm{~m} / \mathrm{s}$.

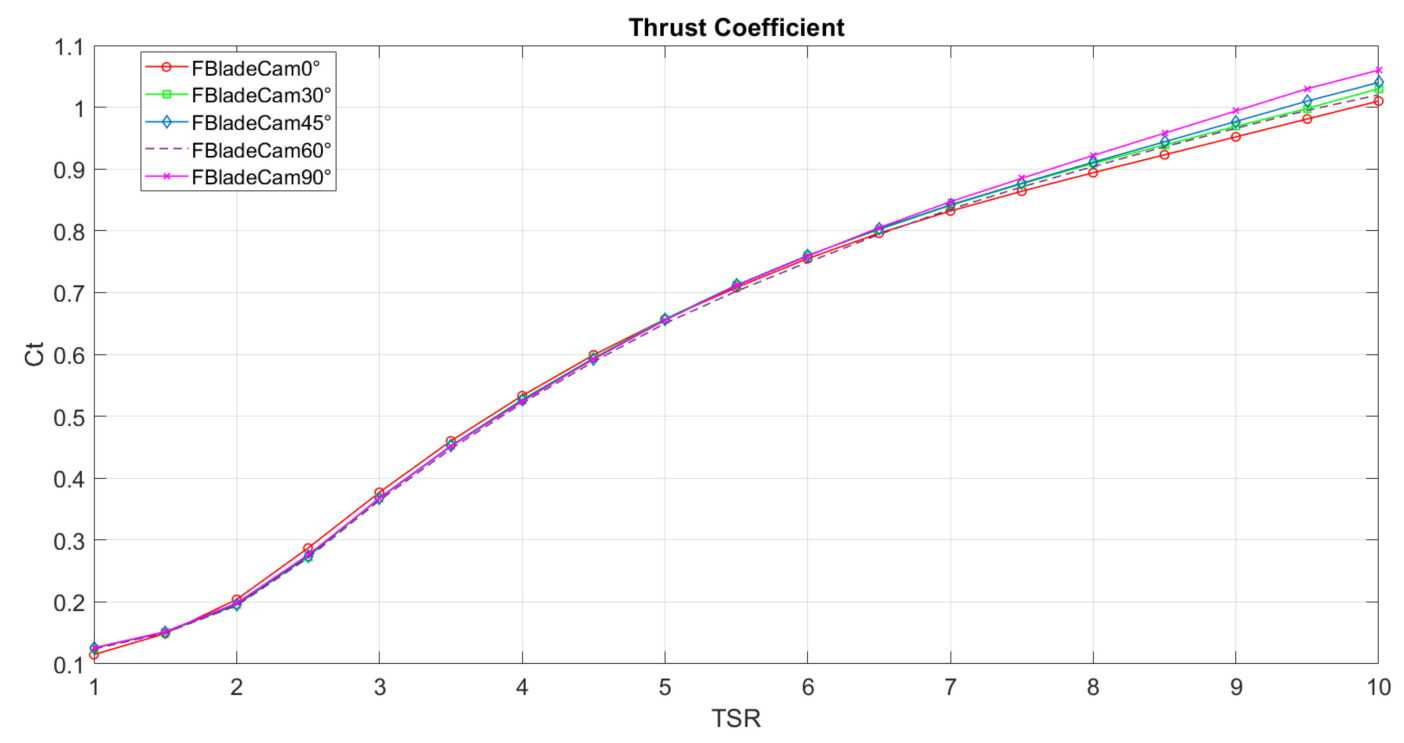

Figure 10. Thrust Coefficient vs TSR at $6 \mathrm{~m} / \mathrm{s}$.

\section{Results and Discussion}

The BEM method and the computational simulation strategy were presented in the last section. The results and discussion are presented in this section to compare and discuss the performance and the advantages of the flexible blade compared to the blade design without a deformation mechanism. The results were calculated using QBlade $^{\circledR}$, and the power output data were analyzed to compare the performance of the different configurations of the flexible blade.

The simulation results of the rotor are presented in Table 2; this set of data were obtained from the several calculations plotted with the different simulation parameters of the flexible blade (see Figure 11). It can be observed how the power coefficient varies as well as the power generated at the different positions of the cam. The minimum variation in power calculation for similar $C_{p}$ values are due to rounding of the decimal numbers shown in Table 2. 
Table 2. $C_{p}$, power, and rotor rotation speed vs wind speed.

\begin{tabular}{ccccccc}
\hline & Cam Angle & $\mathbf{0}^{\circ}$ & $\mathbf{3 0}^{\circ}$ & $\mathbf{4 5}^{\circ}$ & $\mathbf{6 0}^{\circ}$ & $\mathbf{9 0}^{\circ}$ \\
\hline $\begin{array}{c}\text { Wind } \\
\text { Velocity } \\
(\mathbf{m} / \mathbf{s})\end{array}$ & $\mathbf{C} \boldsymbol{p}$ & $\mathbf{0 . 4 0 7}$ & $\mathbf{0 . 4 1}$ & $\mathbf{0 . 4 0 7}$ & $\mathbf{0 . 4 0 1}$ & $\mathbf{0 . 3 9 8}$ \\
\hline 1 & & Power (W) & Power (W) & Power (W) & Power (W) & Power (W) \\
2 & 17.4 & 7.1 & 7.2 & 7.2 & 7.1 & 7.1 \\
3 & 34.8 & 57.1 & 57.4 & 57.3 & 57.2 & 56.9 \\
4 & 52.2 & 192.9 & 194.0 & 193.4 & 192.9 & 191.9 \\
5 & 69.6 & 457.1 & 459.9 & 458.3 & 457.4 & 455.1 \\
6 & 87.0 & 892.9 & 898.3 & 895.2 & 893.3 & 888.8 \\
7 & 104.3 & 1542.9 & 1552.3 & 1546.9 & 1543.6 & 1535.9 \\
8 & 121.7 & 2450 & 2464.9 & 2456.4 & 2451.2 & 2438.9 \\
\hline
\end{tabular}
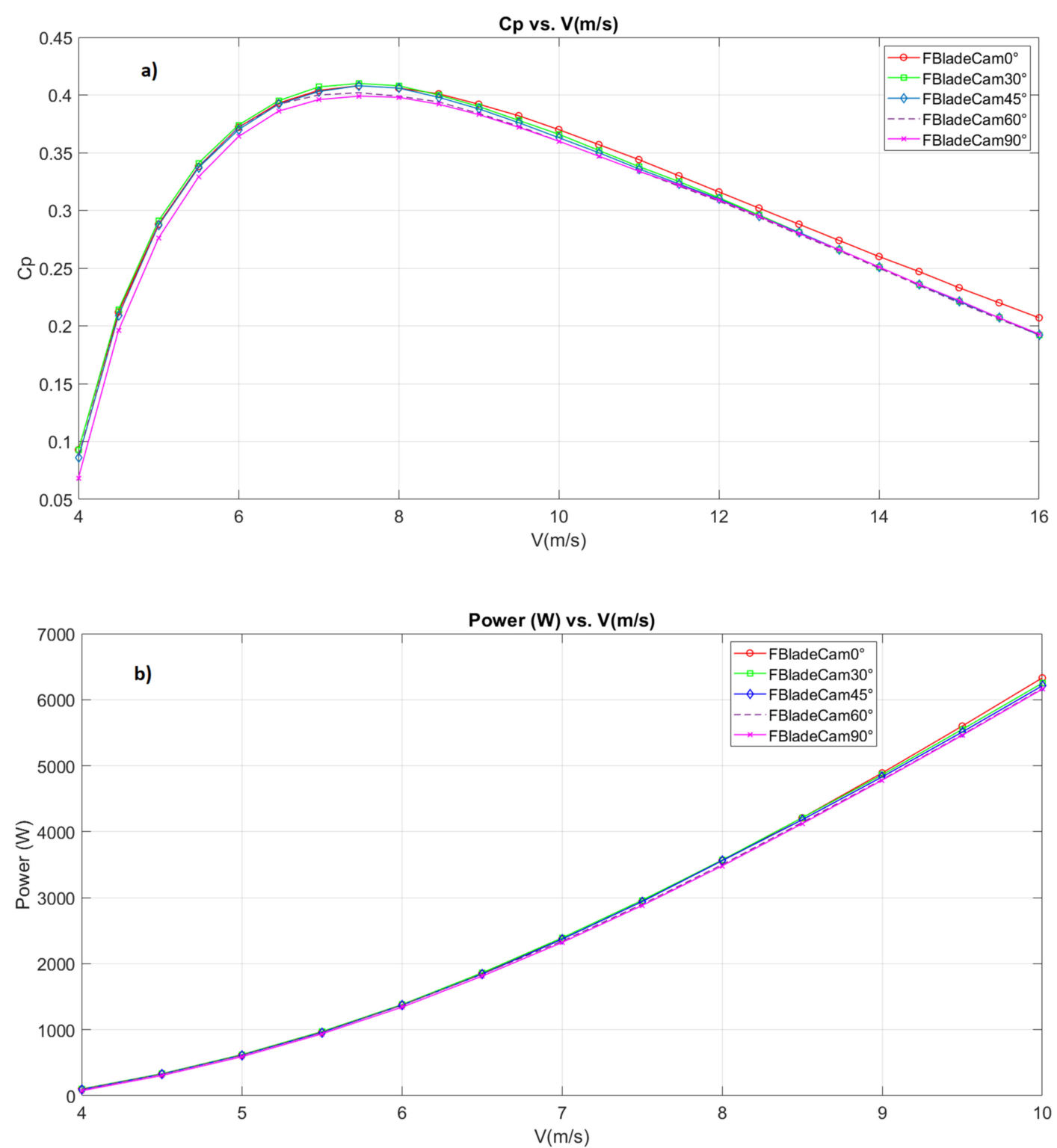

Figure 11. $C_{p}$ vs wind velocity $(\mathrm{m} / \mathrm{s})(\mathbf{a})$ power $(W)$ vs. wind velocity $(\mathrm{m} / \mathrm{s})(\mathbf{b})$.

To illustrate the effect of the position of the cam mechanism along the flexible blade, Figure 12 shows the summary of the maximum (polar) lift and drag coefficients of the aerodynamic profiles along the length of the blade when changing the position of the cams 
at $0,30,45,60$, and $90^{\circ}$; it is detected how this relationship increases by varying the position of the cam in the intermediate sections of the blade, mainly between 1.0 and $2.3 \mathrm{~m}$. In contrast, at the base and the tip there was no variation since the mechanism did not modify these sections. Despite this increase in the $C_{L} / C_{D}$ ratio, in Table 2 it is possible to observe that this effect does not significantly impact the output power and $C_{p}$.

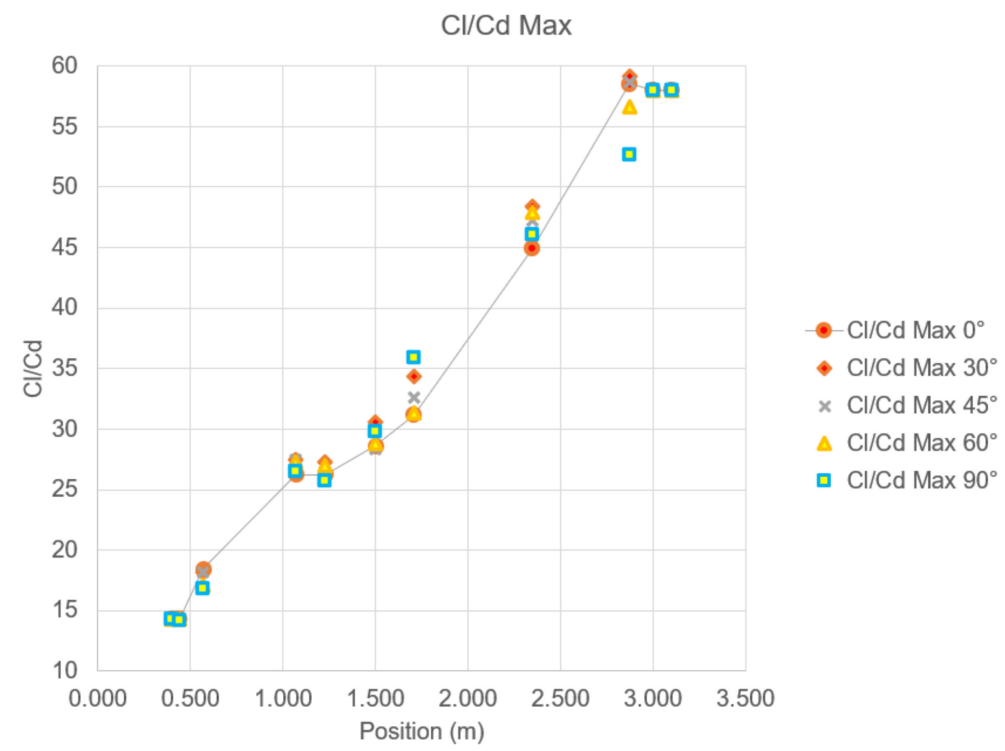

Figure 12. Relationship of maximum lift and drag coefficients ratio for different positions of the cam mechanism along the blade.

One crucial aspect to take into account is the fact that the angle of attack of the intermediate positions of the blade shows a drastic variation when the position of the cam changes from $0^{\circ}$ to $30^{\circ}$ (Figure 13); this confirms that in the $30^{\circ}$ position there is an increase in the power coefficient in comparison with 45,60 , and $90^{\circ}$ positions; however, at the tip and root blade there were no relevant angle variations and, therefore, this did not contribute to a significant increase in the aerodynamic efficiency in the turbine.

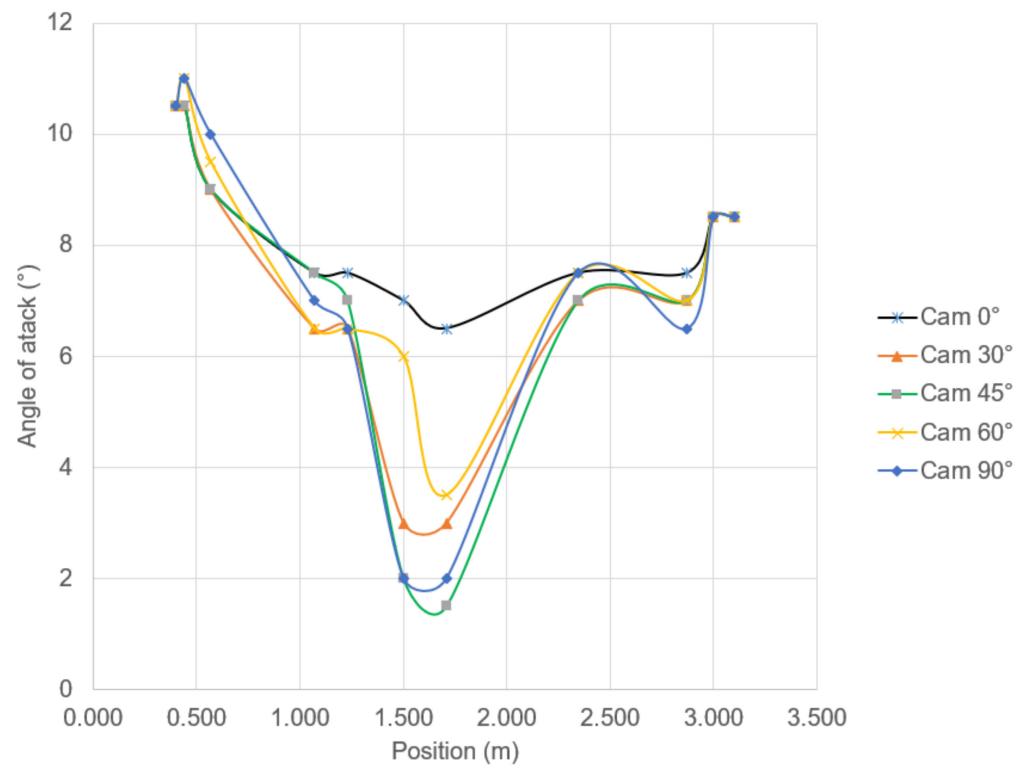

Figure 13. Angle of attack $\left(^{\circ}\right)$ vs Blade position $(\mathrm{m})\left(0,30,45,60\right.$, and $90^{\circ}$ cam angle).

The analysis of the effect of using the flexible blade on aerodynamic efficiency resulted in minimal increases in power output for different wind conditions; however, Figure 14 
shows the plot of the bending moment versus wind velocity. According to the figure, it is suggested that the camber morphing mechanism presented in this article can be implemented as a load control system that allows for the variation in the angle of the cam mechanism depending on the wind conditions. Concerning the simulation data, a decrease of up to approximately $6 \%$ (see Figure 14) can be observed for speeds greater than $10 \mathrm{~m} / \mathrm{s}$, while at lower speeds, the configuration of the flexible blade can be changed to maintain the best performance of generated power.

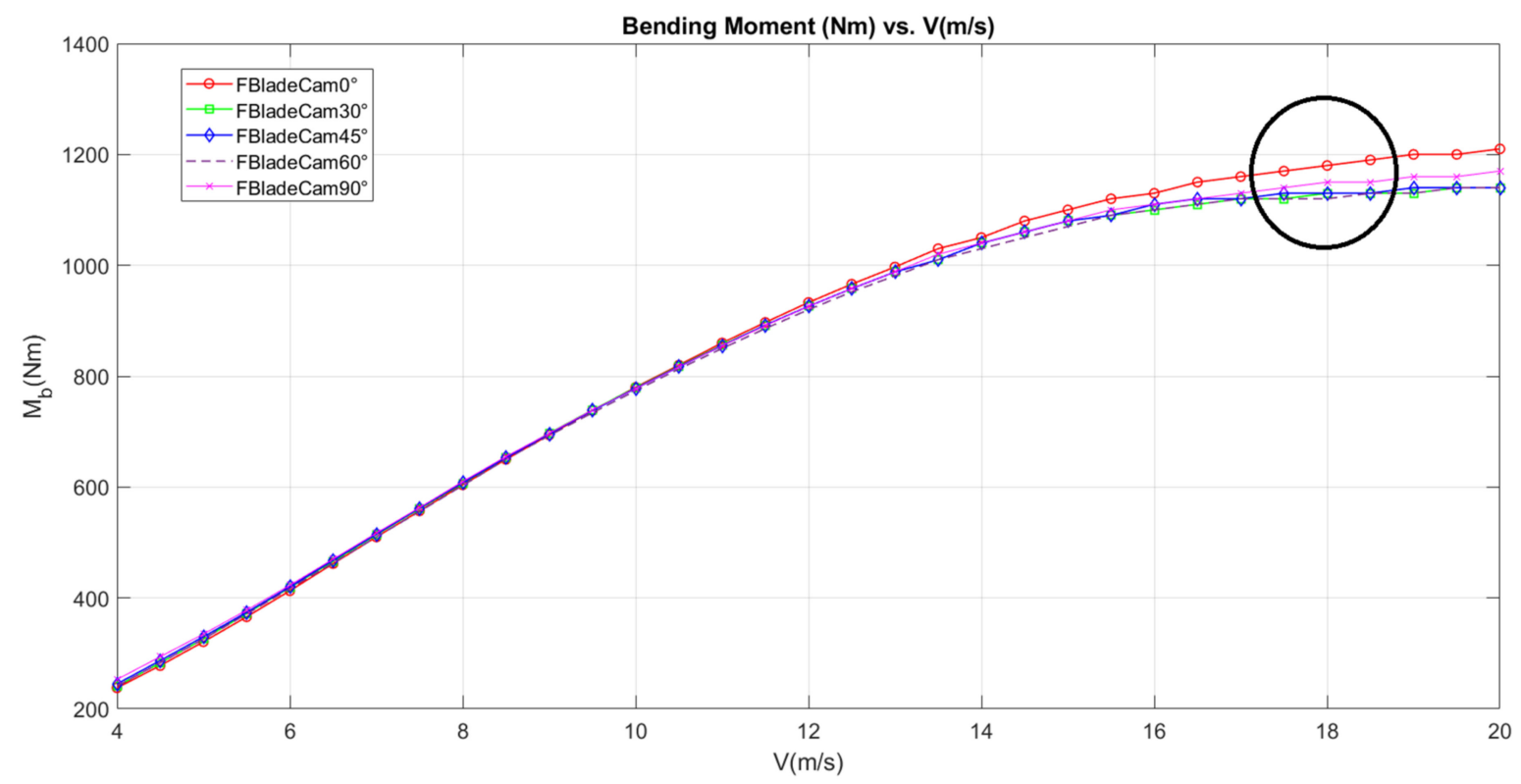

Figure 14. Bending Moment (Nm) vs wind velocity $(\mathrm{m} / \mathrm{s})\left(0,30,45,60\right.$, and $90^{\circ}$ cam angle).

The plot in Figure 15 presents the trend of the thrust coefficient to the wind velocity; the plot values confirm that the flexible turbine rotor can be used to reduce and mitigate extreme and fatigue loads.

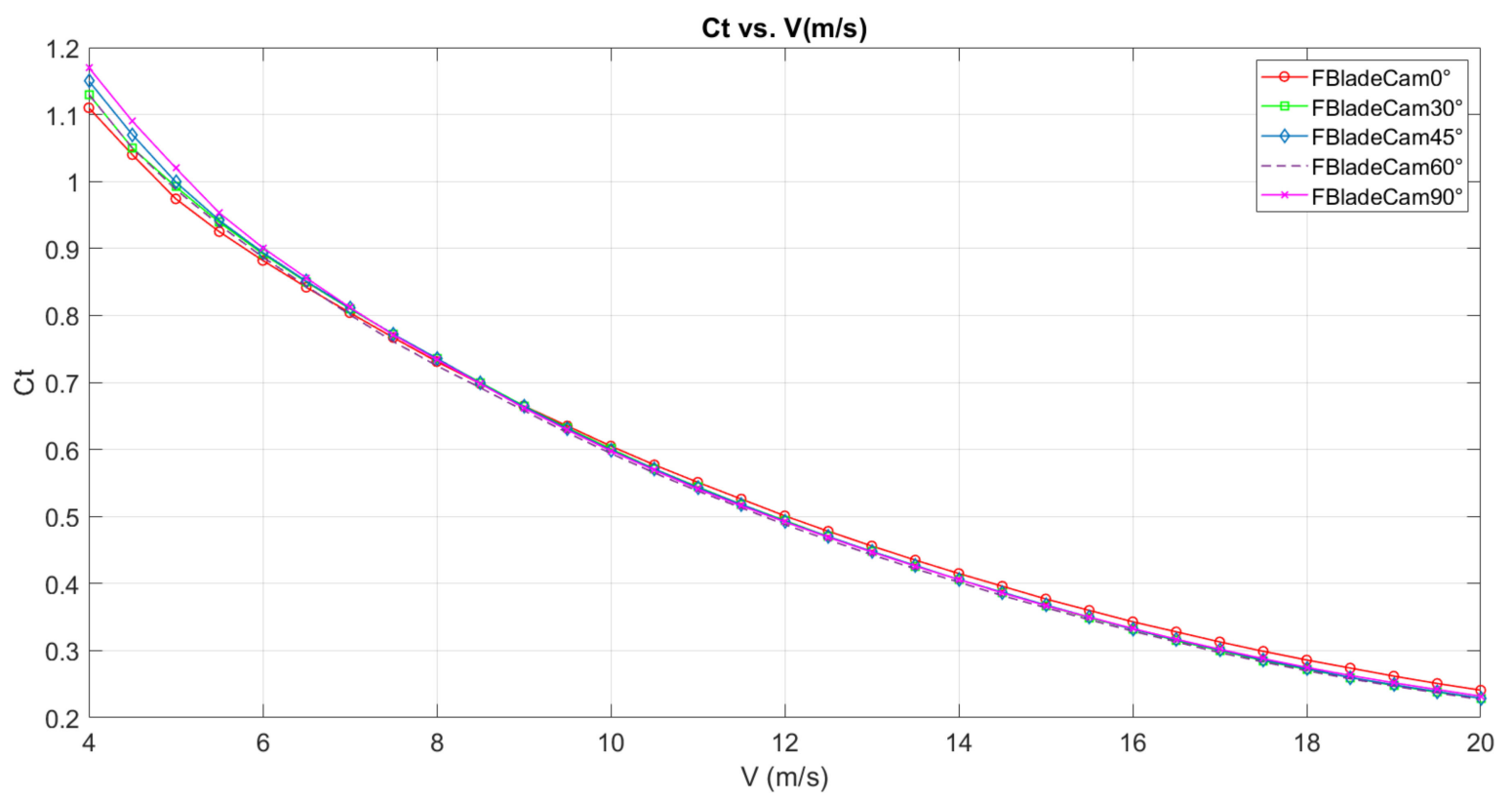

Figure 15. Thrust Coefficient vs wind velocity $(\mathrm{m} / \mathrm{s})\left(0,30,45,60\right.$, and $90^{\circ}$ cam angle).

This analysis has demonstrated the promising potential of using active mechanisms to deform the blades in the new generation of wind turbines. Despite the results obtained 
in this article, it is strongly recommended for new studies to be carried out in the future, including experimental tests and the development of a control model.

\section{Conclusions}

Recently, several studies using smart rotors in wind turbines have demonstrated the capabilities of these load control technologies in extreme load mitigation, alleviation of fatigue loads, as well as the increase in the power output performance, allowing the wind turbines to adapt to variable operating conditions. This article presented the simulation analysis of a small horizontal axis wind turbine power with flexible blades based on the paper presented by Jauregui et al. [22]. The several values of the measurement points were obtained through the high precision dial sensor in order to model the different rotor geometries at different cam angles of the flexible blade.

The effects on the aerodynamic efficiency of the change in the cam angle position in the blade sections were analyzed through the BEM method.

The simulation results implemented in the QBlade ${ }^{\circledR}$ software revealed minimal changes in the output power and the $C_{p}$ for the different wind conditions. It strongly suggests modifying the design at the tip and root of the flexible blade to obtain better results in the power output performance; nevertheless, the data obtained for the thrust coefficient and the average bending moment in Figures 14 and 15 advocate that the flexible blade design could be used to mitigate extreme and fatigue loads. According to the simulation data, a decrease of up to approximately $6 \%$ of the mean bending moment was observed.

The results of this article demonstrated the benefits of using a flexible blade based on a simple cam mechanism to reduce loads in wind turbine rotors. In addition, the mechanism proposed in this paper allows modifying multiple airfoil sections of the blade using a single actuator element in comparison with the different existing shape morphing mechanisms $[8,10,16,17]$ that modify the blade profile implementing multiple actuators, thus, the presented flexible blade reduces energy consumption by active control elements, and the investment and maintenance costs.

New studies are required to define a control model and the implementation of an instrumentation system to integrate these flexible blades as a smart rotor system. These control and instrumentation models will represent new challenges as well as the opening to new lines of research on the subject.

For future work, an analysis of stresses and fatigue is necessary to determine the benefit of deforming aerodynamic profile in the lifetime of the wind turbine rotor. It is strongly advocated to conduct a redesign so that the smart rotor can achieve higher $C_{p}$ in the wind speeds range; this could include different cam individual position angles along the blade sections.

Author Contributions: Conceptualization, A.D.C., J.C.J.-C., F.H., K.K.C.-V., J.A.F., Q.H.-E., A.-J.P.-M. and A.A.; methodology, A.D.C., J.C.J.-C., F.H., K.K.C.-V., J.A.F., Q.H.-E., A.-J.P.-M. and A.A.; formal analysis, A.D.C., J.C.J.-C., F.H., K.K.C.-V., J.A.F., Q.H.-E., A.-J.P.-M. and A.-J.P.-M.; investigation, A.D.C., J.C.J.-C., F.H., K.K.C.-V., J.A.F., Q.H.-E., A.-J.P.-M. and A.A.; writing-review and editing, A.D.C., J.C.J.-C., F.H., K.K.C.-V., J.A.F., Q.H.-E., A.-J.P.-M. and A.A. All authors have read and agreed to the published version of the manuscript.

Funding: This material is based upon work supported by 2018 ConTex collaborative projects funded by the University of Texas System, number 1000002471, and the Consejo Nacional de Ciencia y Tecnología de México, number 2018-94B.

Institutional Review Board Statement: Not applicable.

Informed Consent Statement: Not applicable.

Data Availability Statement: Not applicable.

Conflicts of Interest: The authors declare no conflict of interest. 


\section{References}

1. Gielen, D.; Boshell, F.; Saygin, D.; Bazilian, M.D.; Wagner, N.; Gorini, R. The Role of Renewable Energy in the Global Energy Transformation. Energy Strategy Rev. 2019, 24, 38-50. [CrossRef]

2. Global Energy Transformation: A Roadmap to 2050 (2019 Edition). Available online: https://www.irena.org/publications/2019 /Apr/Global-energy-transformation-A-roadmap-to-2050-2019Edition (accessed on 22 June 2021).

3. Zhang, C.; Plestan, F. Individual/Collective Blade Pitch Control of Floating Wind Turbine Based on Adaptive Second Order Sliding Mode. Ocean Eng. 2021, 228, 108897. [CrossRef]

4. Colombo, L.; Corradini, M.L.; Ippoliti, G.; Orlando, G. Pitch Angle Control of a Wind Turbine Operating above the Rated Wind Speed: A Sliding Mode Control Approach. ISA Trans. 2020, 96, 95-102. [CrossRef] [PubMed]

5. Wiens, M.; Meyer, T.; Wenske, J. Exploiting Bend-Twist Coupling in Wind Turbine Control for Load Reduction**This Research Was Carried out in the Scope of the SmartBlades2 Project (0325601A/B/C/D), Funded by the German Federal Ministry for Economic Affairs and Energy (BMWi) Based on a Decision of the Parliament of the Federal Republic of Germany. IFAC-PapersOnLine 2020, 53, 12139-12144. [CrossRef]

6. Chen, B.; Hua, X.; Zhang, Z.; Nielsen, S.R.K.; Chen, Z. Active Flutter Control of the Wind Turbines Using Double-Pitched Blades. Renew. Energy 2021, 163, 2081-2097. [CrossRef]

7. Bernhammer, L.O.; Van Kuik, G.A.M.; Breuker, R.D. Fatigue and Extreme Load Reduction of Wind Turbine Components Using Smart Rotors. J. Wind. Eng. Ind. Aerodyn. 2016, 154, 84-95. [CrossRef]

8. Oltmann, N.-C.; Sobotta, D.; Hoffmann, A. Load Reduction of Wind Turbines Using Trailing Edge Flaps. Energy Procedia 2017, 136, 176-181. [CrossRef]

9. Sun, X.; Dai, Q.; Menon, M.; Ponta, F. Design and Simulation of Active External Trailing-Edge Flaps for Wind Turbine Blades on Load Reduction. J. Aerosp. Eng. 2017, 30, 04017062. [CrossRef]

10. Chen, H.; Qin, N. Trailing-Edge Flow Control for Wind Turbine Performance and Load Control. Renew. Energy 2017, 105, 419-435. [CrossRef]

11. Boulamatsis, A.M.; Barlas, T.K.; Stapountzis, H. Active Control of Wind Turbines through Varying Blade Tip Sweep. Renew. Energy 2019, 131, 25-36. [CrossRef]

12. Lachenal, X.; Daynes, S.; Weaver, P.M. Review of Morphing Concepts and Materials for Wind Turbine Blade Applications. Wind. Energy 2013, 16, 283-307. [CrossRef]

13. Jost, E.; Lutz, T.; Krämer, E. A Parametric CFD Study of Morphing Trailing Edge Flaps Applied on a 10 MW Offshore Wind Turbine. Energy Procedia 2016, 94, 53-60. [CrossRef]

14. Rasmussen, T.W.; Johansen, A. Small Wind Turbine for Variable Speed with Flexible Blades and Automatically Mechanical Pitching. In Proceedings of the 2017 52nd International Universities Power Engineering Conference (UPEC), Heraklion, Greece, 28-31 August 2017; pp. 1-5.

15. Momeni, F.; Sabzpoushan, S.; Valizadeh, R.; Morad, M.R.; Liu, X.; Ni, J. Plant Leaf-Mimetic Smart Wind Turbine Blades by 4D Printing. Renew. Energy 2019, 130, 329-351. [CrossRef]

16. Alejandro Franco, J.; Carlos Jauregui, J.; Toledano-Ayala, M. Optimizing Wind Turbine Efficiency by Deformable Structures in Smart Blades. J. Energy Resour. Technol. 2015, 137, 051206. [CrossRef]

17. Alejandro Franco, J.; Carlos Jauregui, J.; Carbajal, A.; Toledano-Ayala, M. Shape Morphing Mechanism for Improving Wind Turbines Performance. J. Energy Resour. Technol. 2017, 139, 051214. [CrossRef]

18. Khakpour Nejadkhaki, H.; Hall, J.F. A Design Methodology for a Flexible Wind Turbine Blade With an Actively Variable Twist Distribution to Increase Region 2 Efficiency. In Proceedings of the IDETC-CIE2017 43rd Design Automation Conference, Cleveland, OH, USA, 6-9 August 2017; Volume A2.

19. Cognet, V.; Du Pont, S.C.; Thiria, B. Material Optimization of Flexible Blades for Wind Turbines. Renew. Energy 2020, 160, 1373-1384. [CrossRef]

20. MacPhee, D.W.; Beyene, A. Performance Analysis of a Small Wind Turbine Equipped with Flexible Blades. Renew. Energy 2019, 132, 497-508. [CrossRef]

21. Zhuang, C.; Yang, G.; Zhu, Y.; Hu, D. Effect of Morphed Trailing-Edge Flap on Aerodynamic Load Control for a Wind Turbine Blade Section. Renew. Energy 2020, 148, 964-974. [CrossRef]

22. Jauregui, J.; Herbert, F.; Castillo, K. A Shape-Morphing Subsystem for Small Wind Energy Conversion Systems; American Society of Mechanical Engineers: New York, NY, USA, 20 September 2021; Volume 84249, p. V012T42A020, Virtual, Online.

23. Marten, D. QBlade Short Manual v0.8; TU Berlin: Berlin, Germany, 2014. [CrossRef]

24. Marten, D.; Wendler, J.; Pechlivanoglou, G.; Nayeri, C.N.; Paschereit, C.O. QBlade: An Open Source Tool for Design and Simulation of Horizontal and Vertical Axis Wind Turbines. Int. J. Emerg. Technol. Adv. Eng. 2013, 3, $264-269$. 